\title{
INDICADORES PARA A QUALIDADE SOCIAL EM EDUCAÇÃO DE JOVENS E ADULTOS NO CONTEXTO DA DIVERSIDADE: HORIZONTES E ADVERSIDADES
}

\author{
M. A. AZEVEDO ${ }^{1 *}$, A. M. B. N. TAVARES $^{1}$, S. C. F. MAIA ${ }^{1}$ e M. A. QUEIROZ ${ }^{2}$ \\ ${ }^{1}$ Instituto Federal de Educação, Ciência e Tecnologia do Rio Grande do Norte - IFRN \\ ${ }^{2}$ Universidade Federal do Rio Grande do Norte - UFRN \\ marcio.azevedo@ifrn.edu.br
}

Artigo submetido em novembro/2014 e aceito em dezembro/2014

DOI: $10.15628 /$ holos.2014.2523

\section{RESUMO}

O presente artigo é resultado de pesquisa desenvolvida com fomento do edital universal 2011 do CNPq, visando à construção de indicadores da qualidade educativa para a educação de jovens e adultos no contexto da diversidade, tendo como parâmetro os índices e os indicadores oficiais, bem como aqueles decorrentes das ofertas dos sistemas oficiais de educação - estado e municípios -, além dos programas e projetos desenvolvidos em espaços escolares e não escolares, em municípios da Região do Mato Grande norte-rio-grandense. Para a realização dos estudos, adotamos alguns procedimentos teórico-metodológicos, como a revisão bibliográfica, consulta em banco de dados oficiais, como o IBGE, análise documental, produção de fotografias, notas de campo e aplicação de questionário aberto junto às Secretarias Municipais de Educação de alguns municípios da região do Mato Grande que trabalham com a EJA. Em que pese reconhecer os avanços, como a ampliação das ofertas e a implementação de programas e projetos, como o Brasil Alfabetizado, os índices e os indicadores da investigação mostram que as iniciativas governamentais e não governamentais voltadas para a EJA no Brasil e na região do Mato Grande ainda não promovem os resultados esperados, sendo muitas vezes descontínuas e tendo o caráter compensatório. A realização da pesquisa permitiu, assim, a produção do conhecimento acerca da construção de indicadores sociais para a educação de jovens e adultos em espaços escolares e não escolares diversos, além de ter instigado a reflexividade em torno dos desafios e das possibilidades para vislumbrarmos a qualidade social $d a$ educação como um princípio de direito que deve ser garantido pelo Estado brasileiro, tema que vem permeando intensa e tensamente os debates na atual agenda da política educacional.

PALAVRAS-CHAVE: Indicadores Sociais. Educação e Diversidade. Educação de Jovens e Adultos. Qualidade Social

\section{INDICATORS FOR THE SOCIAL QUALITY IN EDUCATION OF YOUTH AND ADULTS IN THE CONTEXT OF DIVERSITY: HORIZONS AND ADVERSITIES}

\begin{abstract}
This paper is the result of a research conducted with promoting universal Public Universal Announcement Contest 2011 CNPq, aiming at the construction of educational quality indicators for the education of youth and adults in the context of diversity, with the parameter indexes and the official indicators, as well as those arising from offers of official education systems - state and municipalities - in addition to the programs and projects developed in school and nonschool, in municipalities in the region of Mato Grande at the Rio Grande do Norte state. For such studies, we adopted some theoretical and methodological procedures, such as literature review, consultation on official database, like the IBGE, document analysis, and production of photographs, field notes and application of open questionnaire to the Municipal Departments of Education in some municipalities in Mato
\end{abstract}

Grande region who work with adult education. Despite recognizing the advances, such as the expansion of the offers and the implementation of programs and projects such as the Brasil Alfabetizado, indexes and research indicators show that the governmental and non-governmental initiatives aimed at adult education in Brazil and the region Mato Grande not promoted the expected results, often discontinuous and taking the compensatory nature. Thus, the research allowed the production of knowledge about the construction of social indicators for the education of youth and adults in school and non-various school, and has instigated reflexivity on the challenges and opportunities for the social quality in education as a principle of law which must be guaranteed by the Brazilian government, a theme that has permeated intense and tightly discussions on the current agenda of educational policy.

KEYWORDS: Social indicators, education and diversity, youth and adult education, social quality. 


\section{INTRODUÇÃO}

O presente artigo resulta de recorte acerca de investigação desenvolvida com fomento do Conselho Nacional de Desenvolvimento e Tecnológico - CNPq, o qual foi aprovado pelo edital universal em 2011. Desde 2010, o Núcleo de Estudos em Educação e Diversidade (NEPED)/IFRN campus João Câmara e o Grupo de Estudos em Linguagem, Formação Profissional Docente e Inclusão Social - GELFOPIS (IFRN/campus Macau) vêm investindo em iniciativas de ensino, pesquisa e extensão voltadas para a EJA, destacando-se, além do PROEJA, os cursos de Pósgraduação lato sensu: especialização em Organização e gestão escolar para a educação do campo e educação de jovens e adultos (aprovada via MEC/DPEJA/SECADI/FNDE); especialização em Educação, sustentabilidade e geografia do semiárido (aprovada pelo Edital 35/2010 - CNPq Linha Temática 4); especialização em Educação do campo - saberes da terra (aprovada via MEC/SECADI/FNDE). No âmbito das atividades de extensão, o campus João Câmara também coordena o projeto Mulheres Mil, destinado à alfabetização e à profissionalização de mulheres que moram nos assentamentos da região.

Para a realização da pesquisa, adotamos alguns procedimentos teórico-metodológicos, como a revisão bibliográfica, consultas em banco de dados oficiais, como o IBGE, análise documental, produção de fotografias, notas de campo e aplicação de questionário aberto junto às Secretarias Municipais de Educação de alguns municípios da região do Mato Grande que trabalham com a educação de jovens e adultos.

A região do Mato Grande é constituída por 15 municípios: Bento Fernandes, Jandaíra, João Câmara, Maxaranguape, Parazinho, Pedra Grande, Poço Branco, Pureza, Rio do Fogo, São Miguel do Gostoso, Taipu, Touros, Caiçara do Norte, São Bento do Norte e Ceará-Mirim, e comporta uma população de 203.507 habitantes, dos quais 98.128 residem na zona urbana e 105.379, no setor rural. Essas localidades têm, caracteristicamente, população inferior a 10.000 habitantes, cujas matrizes socioeconômicas, políticas e culturais são predominantemente rurais, conforme mostra o Plano de Desenvolvimento Sustentável do Território do Mato Grande (RIO GRANDE DO NORTE, 2006).

A região se sobressai estrategicamente em sua geopolítica, visto que se localiza no ponto mais próximo do continente europeu e possui três dos principais eixos rodoviários do estado. Apesar disso, as perspectivas de desenvolvimento na região são preocupantes, sobretudo no que concerne à dimensão socioeconômica, cujos dados revelam uma determinada estagnação. "A realidade atual aponta uma População Ativa com baixo nível de escolarização, o que certamente dificultará a inserção no mercado de trabalho mais exigente em qualificação profissional" (RIO GRANDE DO NORTE, 2006, p. 7, grifo nosso).

Segundo o Plano de Desenvolvimento Sustentável da região do Mato Grande (RIO GRANDE DO NORTE, 2006) e outros estudos como os de Azevedo, Tavares e Dantas (2011), entre os desafios que se impõem à região, podem-se destacar a concentração de terras; as dificuldades de inserção dos produtos no mercado (comercialização); a degradação ambiental; a irregularidade climática; os elevados índices de analfabetismo no meio rural; a base social pouco organizada: pequeno número de organizações com atuação efetiva no território; o baixo nível de associativismo; a ingerência política; a falta de integração institucional; a migração da população 
rural para a zona urbana; o baixo índice de cobertura da assistência técnica estatal; a insuficiência de cursos profissionalizantes; e a falta de capacitação e de educação voltada para a agricultura familiar. Nesse sentido, o Plano de Desenvolvimento Sustentável sobreleva que as políticas públicas e iniciativas governamentais e não governamentais, bem como a sociedade civil organizada, situam-se num contexto de enfretamento político, econômico, social e cultural que exigem práticas e ressignificações no campo das políticas públicas, inclusive e principalmente no campo da educação de jovens e adultos, em que ainda encontramos inúmeros desafios, conforme mencionamos.

Nesse contexto, desenvolvemos a investigação intitulada indicadores para a qualidade social na educação de jovens e adultos no contexto da diversidade, a qual, associada às ações de ensino e de pesquisa já existentes no IFRN, em particular nos campi situados em João Câmara, Ceará-Mirim e Macau, pode contribuir para a análise crítica e propositiva frente aos desafios e às perspectivas das políticas voltadas à educação de jovens e adultos, numa região marcada por evidentes diversidade e desigualdades socioeconômicas, políticas e culturais.

\section{TECENDO OS INDICADORES: HORIZONTES PARA A QUALIDADE SOCIAL EM EDUCAÇÃO DE JOVENS E ADULTOS NO CONTEXTO DA DIVERSIDADE}

Discutir sobre qualidade em educação brasileira é uma complexa e controvertida tarefa, pois implica entender o significado de padrão de qualidade que está inscrito, oficialmente, na Constituição brasileira de 1988, na nova Lei de Diretrizes e Bases da Educação Nacional (LDB/1986) e no Plano Nacional de Educação/PNE (BRASIL, 2001) dentre outros. Na Constituição, apresenta-se no artigo 206, inciso VII, como "[...] garantia de padrão de qualidade" (BRASIL, 1988, p. 138). Na LDB, no título II, artigo 3o, inciso IX, apresenta-se igualmente como princípio; no título III, artigo 4으, inciso IX, esta é a definição de qualidade: “[...] padrões mínimos de qualidade de ensino, definidos como a variedade e a quantidade mínimos, por aluno, de insumos indispensáveis ao desenvolvimento do processo de ensino-aprendizagem".

Nessa definição da LBD, chama a atenção para o que prescreve como atributo "padrões mínimos de qualidade para o ensino" enquanto esses poderiam ser padrões máximos de qualidade (grifos nossos) à semelhança do que se exige da produção material. É também questionável o que segue como critério de qualidade do ensino: "variedade e a quantidade mínimos, por aluno, de insumos indispensáveis". Essa perspectiva minimalista contradiz o que se atribui como educação e ensino com qualidade social referenciada que implica espaços físicos adequados ao trabalho pedagógico (tamanho, ventilação, acessibilidade), materiais e equipamentos que facilitam o ensino e a aprendizagem.

Dentre outros atributos políticos, pedagógicos e técnicos, a qualidade em educação e no ensino requer, ainda, currículo formal que atenda às diversidades e que respeite o currículo real dos estudantes. Os professores e demais profissionais desse campo devem ser devidamente formados para o exercício de suas funções, em especial, o magistério. É imprescindível terem um plano de cargo, carreira e remuneração definido e devidamente cumprido pelo patronato.

Esse aporte legal e as demais políticas de educação pública e gratuita suscitam inúmeras contradições que merecem uma compreensão clara dos princípios e das ideologias que as permeiam. Sem aprofundar o debate, neste texto suscitamos a seguinte reflexão: quando os 
dirigentes políticos e os burocratas do planejamento se referem à educação pública para os setores pobres da população, estão seguindo os ditames de poderes multilaterais materializados em organismos como a Organização Mundial do comércio (OMC), Banco Interamericano do Desenvolvimento (BID) e Banco Mundial.

Os governos nacionais, principalmente na América Latina, e em particular o Brasil, são signatários de decisões em âmbito internacional, a exemplo da Declaração Mundial sobre Educação para Todos (Conferência de Jomtien/1990), para satisfazer as necessidades básicas de aprendizagem. A Cúpula Mundial pelas Crianças (1990) e a Declaração de Manágua (1993) prescrevem sobre uma sociedade baseada na equidade, na justiça, na igualdade e na interdependência. A Declaração de Dakar, texto da Cúpula Mundial de Educação (2000), avalia e reforça os propósitos de Jomtien, dentre outros.

Os objetivos e as metas desse plano são ambiciosos e, portanto, requerem a redefinição das políticas educacionais em termos de recursos financeiros, materiais, formação de pessoal, avaliações que aspirem a processos e resultados com qualidade máxima.

Ao que parece, ainda estamos distantes desse ideal de qualidade, pois as proposições políticas, mesmo aquelas que se dizem contar com a representação de setores da sociedade, ainda são tímidas e não se tornaram efetivas como políticas que atestam qualidade. A LDB (1986) e o Plano Nacional de Educação/PNE, nas suas versões em 2001 e 2010, e igualmente o relatório final da Conferência Nacional de Educação (CONAE), que deveria gerar o novo PNE (2010-2020), não traduzem com clareza, o entendimento sobre qualidade que deve orientar as decisões na formulação e na implementação das políticas nesse campo social.

O documento final da CONAE 2010, eixo II, atribui como qualidade social da educação um conceito amplo que implica determinados princípios e não acena com ações efetivas de sua materialização. Tem como concepção político-pedagógica a garantia dos seguintes princípios: o direito à educação básica e superior, a inclusão em todas as dimensões, níveis, etapas e modalidades, a qualidade social, a gestão democrática e a avaliação emancipatória. No documento, qualidade é assim definida:

[...] direito para todos, por meio de políticas públicas, materializadas em programas e ações articuladas, com acompanhamento e avaliação da sociedade, tendo em vista a melhoria dos processos de organização e gestão dos sistemas e das instituições educativas. Implicam, também, processos de avaliação, capazes de assegurar a construção da qualidade social inerente ao processo educativo, de modo a favorecer o desenvolvimento e a apreensão de saberes científicos, artísticos, tecnológicos, sociais e históricos, compreendendo as necessidades do mundo do trabalho, os elementos materiais e a subjetividade humana (BRASIL, 2010, p. 41).

O termo qualidade, nesse documento, como em outros que o antecedem, é polissêmico e não denota consenso quanto aos atributos ou indicadores de um conceito de qualidade em educação. Pensar sobre qualidade em educação, especificamente a escolarização, implica pensar a escola enquanto organização social, mantendo-se em condições de funcionamento adequadas para promover um ensino qualificado. Essa organização é formada por pessoas, grupos, etnias com crenças e valores distintos; é um espaço no qual se expressam as contradições inerentes às 
desigualdades em suas múltiplas dimensões: econômicas, sociais, políticas, culturais, dentre outras.

Os fatores intraescolares agregam qualidade das condições físicas, materiais, pedagógicas, profissionais. E os fatores extraescolares não se apartam da vida da escola, do seu dia a dia, pois deles depende para desenvolver suas ações de gestão pedagógica, administrativa e financeira. As duas dimensões que requerem qualidade originam-se e convergem para as políticas educacionais.

Nesse sentido, a Organização para Cooperação e Desenvolvimento Econômico (OCDE) e da Organização das Nações Unidas para a Educação, a Ciência e a Cultura (Unesco) consideram uma série de critérios de qualidade em educação: os insumos, os processos e os resultados e o ensino, especificamente aquilo que acontece em sala de sala de aula. Salientam os recursos humanos, os materiais e os resultados de desempenho dos estudantes, acrescidos da infraestrutura da escola que contempla: o ambiente físico, segurança; materiais e equipamentos pedagógicos e administrativos necessários e adequados ao trabalho pedagógico. Ademais, destacam: formação, remuneração, educação dos profissionais da educação, bem como a participação dos segmentos da escola nas decisões e nas atividades. Destacamos, ainda, no âmbito das organizações multilaterais, a concepção de qualidade mantida pelo Banco Mundial que se resume aos princípios da equidade e da eficiência, com o aceno de sistemas nacionais de avaliação, associados a insumos como livro texto, equipamentos, laboratórios dentre outros.

Entendendo que alguns aspectos contemplados nessas concepções de qualidade de educação não são desprezíveis, devemos ficar atentos à natureza ideológica de alguns deles, os quais, por serem restritivos, comprometem os princípios de uma educação emancipatória. Diante desse cuidado, acrescentamos, como atributo fundamental, que as políticas educacionais com vistas à qualidade, devem ser formuladas com bases teóricas e metodológicas que contemplem o ser humano em todas as suas dimensões, em seus direitos individuais e coletivos; devem tomar como referência alguns diagnósticos decorrentes dos contextos socioeconômico, histórico, político, educacional, dentre outros critérios de planejamento, implementação e de avaliação de políticas públicas; devem expressar, assim, as necessidades e as demandas, principalmente, daqueles segmentos da sociedade expropriados dos bens materiais e imateriais; e não devem limitar-se, portanto, aos ditames dos organismos multilaterais, enquanto tradutores das políticas neoliberais, pois a educação de jovens e adultos, a exemplo de outros níveis e modalidades educativas, ainda busca a garantia do direito pleno, gratuito, obrigatório e de qualidade social, sobretudo porque a sua oferta não ocorre exclusivamente nos espaços oficiais de educação.

\section{EDUCAÇÃO DE JOVENS E ADULTOS EM CONTEXTOS DIVERSOS E ADVERSOS}

A Educação de Jovens e Adultos (EJA) é uma modalidade específica da educação básica destinada ao atendimento de alunos que não tiveram na idade própria acesso ou continuidade ao estudo no ensino fundamental e médio, conforme regulamenta o art. 37 da Lei de Diretrizes e Bases da Educação Nacional - Lei n. 9.394/96. Ocorre que, para a consolidação da EJA como uma modalidade educativa inscrita no campo do direito social, é preciso que se supere a concepção de modalidade compensatória, como histórica e politicamente vem ocorrendo no Brasil, já que os seus objetivos não devem se concentrar na recuperação temporal da escolaridade. 
No Brasil, em particular, ingressamos no século XXI diante de uma série de desafios educacionais, sobretudo para as populações pobres e de regiões menos favorecidas socioeconomicamente, que comportam "[...] dentro de si realidades tão desiguais que fazem com que as possibilidades e os desafios da educação permanente também estejam colocados para extensas parcelas de nossa população" (HADADD; DI PIERRO, 2000, p.128). Diante disso, faz-se necessário entender que, além da ampliação da percepção das dimensões de tempo e do espaço no processo ensino-aprendizagem, as propostas político-pedagógicas que atendem aos sujeitos que estudam nessa modalidade educativa devem estabelecer uma relação mais estreita com o seu entorno sociocultural, visando ao desenvolvimento de práticas que vislumbrem uma escola associada à sua vida, identidade e especificidades.

Nesse particular, alguns mecanismos de conscientização são importantes para que o ato educativo seja dimensionado sem as arestas do preconceito social, pois a consciência política e a defesa pelo direito à educação se evidenciam cada vez mais na sociedade, em particular entre a população jovem e adulta excluída de direitos básicos como a educação e o trabalho, conforme mostram Arroyo (2001; 2008; 2009) e Azevedo e Souza Filho (2009).

Em que pese reconhecermos os avanços, como a implementação do PROEJA, os dados oficiais publicados em documentos como os da Unesco (2008), Brasil (2007; 2008) mostram que a EJA no Brasil ainda não ocupa uma posição privilegiada no conjunto das políticas de educação, e os sujeitos vinculados a essa modalidade educativa são marginalizados nas esferas socioeconômicas e educacionais, privados do acesso à cultura letrada e aos bens materiais, comprometendo a participação ativa dos sujeitos no mundo do trabalho, da política e da cultura. Segundo a Unesco (2008b), até 2015 o compromisso do Brasil seria de atingir 50\% nos níveis de alfabetização de adultos. Entretanto, o documento mostra que essa meta só poderá ser alcançada em 2025, vistas as dificuldades político-pedagógicas, como a evasão, descontinuidade nas políticas, falta de respeito à diversidade, desvinculação da educação com o trabalho, entre outros.

Por isso, considerar as heterogeneidades desses sujeitos, suas identidades, suas peculiaridades e expectativas em relação à escola requer a construção de indicadores da qualidade educativa que se pautem no respeito à diversidade, tendo como marco um projeto político-pedagógico que desenvolva um processo educacional com qualidade socialmente referenciada; processos formativos de educação (inicial e continuada); vínculos com o mundo do trabalho (ANTUNES, 2011; SOARES, 2010); e as práticas sociais emancipatórias. Isso exige a compreensão de que a educação é um processo permanente, contínuo e ininterrupto ao longo da vida (DELORS, 2003; DINIZ, 2009; BEISIEGEL, 2008).

Nos anos 2000, as ações decorrentes do Plano de Desenvolvimento da Educação - PDE, associadas às lutas e conquistas consolidadas na agenda governamental das políticas de educação, ampliaram as possibilidades de inclusão da EJA no plano da educação profissional. Disso resultou, por exemplo, a implementação do Programa Nacional de Integração da Educação Profissional com a Educação Básica na Modalidade de Educação de Jovens e Adultos (PROEJA), sendo instituído por meio do Decreto n. 5.840, de 13 de julho de 2006, conforme mostra Moura (2006; 2008). Tendo como objetivo se constituir em uma política de inclusão social emancipatória, parte da compreensão de que a escola é um locus integrante e atuante nas dinâmicas sociais, devendo contribuir para o desenvolvimento das vocações produtivas e das 
potencialidades de desenvolvimento regional, envolvida em ações de sustentabilidade sociocultural, econômica e ambiental.

A crise da instituição escolar não pode ser compreendida sem levar em consideração alguns fatores considerados cruciais: as condições atuais de expansão e internacionalização da economia capitalista, num contexto de hegemonia ideológica neoliberal, bem como a emergência do "capitalismo informacional"; as mutações aceleradas nas formas de organização do trabalho; e a inevitabilidade, também, em grande medida, ideologicamente construída, do desemprego estrutural.

A referida tensão da educação em função das pressões sociais permitem que os espaços educativos, quase sempre passivamente, sejam o "bode expiatório" para as crises econômicas cada vez mais frequentes. Os discursos da teoria do capital humano induzem os cidadãos a pensar que a falta de emprego é devido à não qualificação dos indivíduos, sendo esta, por sua vez, acriticamente atribuída à incapacidade estrutural das propostas educativas para preparar os estudantes em função das (supostas) necessidades da economia (MCLAREM, 1996).

No âmbito da política pública social, a EJA deve ser considerada como importante mecanismo das políticas educativas para a melhoria da qualidade da inclusão social por meio da atenção pedagógica de espaços escolares e/ou não escolares. No Brasil, particularmente, a temática ganha destaque no discurso legal das políticas governamentais voltadas para a educação, tendo em vista a grande quantidade de adultos analfabetos ou com baixa escolaridade, realidade que tributa ao Brasil o 80 lugar na conjuntura mundial com o maior número de excluídos escolares.

Tais políticas, a partir dos anos 1990, passam a balizar como orientação pedagógica: o reconhecimento da Educação de Jovens e Adultos como direito; a alfabetização articulada com a continuidade da Educação de Jovens e Adultos com foco na cidadania; o respeito às diversidades: étnico-racial, cultural, de gênero, social, ambiental e regional; e a perspectiva interdisciplinar e intersetorial da Educação de Jovens e Adultos.

Nesse ínterim, destacamos como documentos de referência para a EJA o Documento Nacional Preparatório à VI CONFINTEA; o Marco de Ação de Belém - VI Conferência Internacional de Educação de Jovens e Adultos; o Plano de Desenvolvimento da Educação - PDE; o documento final da Conferência Nacional de Educação - CONAE; a proposta do Plano Nacional de Educação PNE 2011-2020; e o Plano de Ações Articuladas - PAR.

A formação do educando jovem e adulto requer um vínculo pedagógico emancipador da escola com o pressuposto da educação social. São perspectivas que conduzem ao desenvolvimento humano, com relação à oportunidade de acolhimento sociocognitivo dos excluídos sociais, sejam em espaços escolares ou não escolares.

A educação de qualidade social para jovens e adultos requer uma formação que deve ser permeada transversalmente por reflexões, críticas e pesquisas sobre epistemologias, políticas e metodologias específicas de EJA que assegurem a formação de conceitos e que mobilizem a diversidade dos saberes na perspectiva da transformação social (FREIRE, 2003).

O estudante da EJA possui um perfil ajustado com suas histórias de vida marcadas por experiências, saberes, hábitos, atitudes e valores. Pensar em uma concepção pedagógica para a sua inclusão social requer referências teórico-práticas permeadas de saberes que sustentem as 
ações pedagógicas críticas, reflexivas e com ênfase em pesquisa, em atenção a um projeto de educação libertadora.

Nesse sentido, destacamos que as ações de educação, em espaços escolares e não escolares, que atendem sujeitos excluídos no Brasil, revelam a existência de "um modelo formativo", identificado por Paulo Freire (2003), como modelo hegemônico da formação, que envolve tendências do racionalismo técnico e da formação na ótica academicista e tradicional. Nesse modelo, o professor e o aluno são reprodutores de saberes produzidos por outros atores sociais.

Essa concepção de educação tradicional é baseada em determinadas características, tais como: treinamento de habilidades (identificadas como competências); conteúdos descontextualizados da realidade e distante do processo educativo da escola, dicotomia teoriaprática; corpo docente composto de mediadores que não tiveram acesso ao estudo de conteúdos curriculares sobre educação social e pedagogia social, salvo raros momentos, o que dificulta a mobilização desses saberes da profissão na prática cotidiana.

Outras questões ligadas às situações de dificuldade na realização de Educação de Jovens e Adultos ocorrem em função da fragilidade dos contextos formativos, muitas vezes prédios precários, improvisados, marcados por interesses assistencialistas, saberes fragilizados dos professores formadores sobre a área. Portanto, evidencia-se a necessidade de se sugerirem ideias teóricas comprometidas com o atendimento social na EJA que contribuam para a superação de obstáculos da inclusão social e, sobretudo, que lancem alternativas de configurações de formação verdadeiramente formadora de sujeitos crítico-reflexivos.

$\mathrm{Na}$ especificidade dos contextos de EJA, no espaço escolar e não escolar, é de fundamental importância a reflexão sobre a compreensão curricular problematizadora, o uso intencional de diferentes metodologias, o domínio do conteúdo libertador, a veiculação de um conhecimento construído processualmente, a análise da educação como um compromisso político coerente com valores éticos e morais, o desenvolvimento da pessoa e a colaboração entre iguais. Nesse parâmetro de educação, questiona-se o ensino eminentemente escolaresco, técnico, acabado e formal (AFONSO, 2001).

Para os estudiosos (FREIRE, 2003; ROMANS, 2003; GOHN, 2010; GADOTTI, 2013) a escola emancipadora, ou em outras palavras, a escola de educação social, ou ainda concebida como a escola cidadã, deve ser complexa e diversificada, devendo exercer outras funções: motivação, luta contra a exclusão social, participação das estruturas sociais, entre outras. Nesse sentido, entende-se que, para o alcance de tal realização, se faz necessária uma nova configuração de escola que contemple a perspectiva de reflexão em grupo, processo coletivo para regular as ações e processo coletivo para regular as decisões sobre inserção social.

Os espaços educativos continuam a fabricar apatia, desinteresse e desigualdade, e uma das suas reações tem sido a violência na escola, ou seja, a opressão combatida/respondida pela força bruta. Continua válida a observação de Paulo Freire de que "[...] o grande problema está em como poderão os oprimidos, que hospedam o opressor em si, participar da elaboração, como seres duplos, inautênticos, da pedagogia da sua libertação" (FREIRE, 1996, p. 32). E sabemos todos que parte significativa da opressão acentua-se, hoje, no binômio globalização econômica e neoliberalismo comercial, confabuladores centrais da exclusão social. 
Freire (1996) explicita ainda que o campo do currículo como área de disputa ferrenha de interesses políticos em torno dos processos educativos e, como núcleo central dessas disputas, as questões relativas à formação educativa. Sua ênfase política recai principalmente sobre: (a) o direito de conhecerem melhor o que já conhecem da experiência feita; (b) o direito de conhecerem o que foi apropriado pelos opressores e lhes foi negado; e (c) o direito de produzirem o seu próprio conhecimento (inerente aos seus próprios valores, interesses e necessidades sociais, culturais e políticas). Todos sabemos da sua forte defesa da educação problematizadora, precisamente porque, no seu contexto, os oprimidos teriam vez e voz para discutirem seus problemas e as saídas organizadas para eles.

A metodologia é um outro ponto crucial para a construção de uma pedagogia social libertadora para o espaço escolar e não escolar. A metodologia para Freire deve focar-se na noção política da ação dialógica. Podemos dizer que a educação por meio da composição curricular e do diálogo são arenas políticas nas quais os conhecimentos convergentes, divergentes e antagônicos combatem, e, nesse combate, os oprimidos só podem mostrar sua fortaleza na ação coletiva dialógica de enfrentamento de quem os oprime.

Nesse caminho, os debates sobre educação social precisam ser tecidos em conjunto complexo e compostos pelos campos pedagógico, gnosiológico, cultural, político, dialógico, social, antropológico. Uma educação contribuinte para o desenvolvimento humano precisa se nutrir, necessariamente, de uma pedagogia da esperança e da ousadia para combater a pedagogia do fatalismo e do medo. Precisa estar apta a garimpar e a escalar a autonomia para que seus protagonistas persigam a utopia, o inédito que seja viável, enfim, a história como possibilidade do novo, da mudança. Para Freire (1993),

Como processo de conhecimento, formação política, capacitação científica e técnica, a educação é prática indispensável aos seres humanos e deles específica na História como movimento, como luta. A história como possibilidade não prescinde da controvérsia, dos conflitos que, em si mesmos, já engendrariam a necessidade da educação (FREIRE, 1993, p.14).

Freire propõe uma epistemologia que investe no respeito às diferenças, à diversidade, às questões de gênero, de etnia, dos direitos responsáveis por uma cidadania plena, planetária e multicultural para os que não tiveram (ou tiveram pouca) voz e vez e que continuam a se espalhar pelo mundo como sem-terra, sem-pão, sem-teto, sem-escola nenhuma ou sem-escolade-qualidade, sem-emprego, sem-paz e, principalmente, sem-esperança (SCOCUGLIA, 2004).

A educação de jovens e adultos libertadora é um convite a pensar o desenvolvimento humano como um fenômeno social e epistemológico. Consiste em um processo de formação humana, ou de hominização, como diria Paulo Freire. É de natureza social e sofre interferência das condições existenciais que demarcam os aspectos subjetivos, culturais, materiais, históricos, entre outros, em que homens e mulheres se constituem humanos.

São as vítimas que, quando interrompem a história, criam o novo (DUSSEL, 2000). Os espaços escolares e não-escolares de atenção à EJA devem ser vistos como ambientes éticolibertadores e cognitivos das vítimas do sistema. A educação de jovens e adultos ainda merece superar a ideia de oferta que se dá para os que estão em atraso, fora da idade escolar, inclusive porque ainda predomina a ideia de que a diversidade reflete muito mais uma situação de atraso do que de espaços e de sujeitos que têm particularidades. Nesse sentido, percebemos que o 
direito, além de ser negado, muitas vezes, se tornar residual, precário e compensatório. Na verdade, percebemos que, independentemente de onde ocorre, a educação escolar, compreendida como processo permanente e vital aos seres humanos, deve permitir a transformação social e humana, pois dificilmente outro processo como a educação e outros espaços como a escola poderão promover a cidadania plena dos sujeitos (GADOTTI, 2010).

\section{INDICADORES PARA A QUALIDADE SOCIAL EM EDUCAÇÃO DE JOVENS E ADULTOS NO CONTEXTO DA DIVERSIDADE: O QUE REVELAM OS DADOS DA PESQUISA?}

A pesquisa mostrou que a maioria dos professores que atuam nos sistemas oficiais de educação na região do Mato Grande, no Rio Grande do Norte, possui a formação inicial. Mas a ausência de dados no item quantidade de professores sem especialização na área indica que a formação continuada é uma necessidade nos sistemas oficiais de educação, o que já é indicado em estudos como os de Dias (2011). Percebemos também que a faixa etária dos sujeitos é bastante diversa, merecendo maior atenção a ideia do direito à educação longa da vida, bem como a superação de alguns estereótipos que permeiam a EJA, como a concepção de que os jovens e adultos estão fora da idade própria de escolarização ou que não são estudantes regulares.

Observamos também que todas as ofertas da EJA nos municípios investigados se desenvolvem no turno noturno, reforçando assim a necessidade da garantia do direito à educação de jovens e adultos trabalhadores. Chama-nos à atenção o fato de o município de João Câmara não atender à EJA em escolas do campo. Embora não tenhamos coletado informações mais específicas, presumimos que possivelmente significativo contingente de jovens e adultos que moram em espaços rurais podem encontrar-se fora da escola por falta de atendimento in loco, o que já pode se constatar em estudos desenvolvidos pelo Unicef (2012).

O programa Brasil Alfabetizado é regido pela Lei no 10.880, de 09 de junho de 2004, e pela Lei no 11.507, de 20 de julho de 2007, tendo como objetivos: a) incentivar o reconhecimento da EJA como direito; b) induzir a institucionalização da educação de jovens e adultos como política pública; c) apoiar a ampliação da oferta e a melhoria da qualidade da educação de jovens e adultos na perspectiva da educação continuada, entendendo a aprendizagem como processo que se dá em diferentes espaços e em todas as dimensões da vida; e d) promover e apoiar as diferentes formas de educação, formal e não formal, para jovens e adultos.

Para atingi-los, a DPEJA/SECADI priorizou como foco os seguintes eixos: financiamento; oferta de formação qualificada; elaboração, produção e distribuição de materiais didáticos e literários; fomento a políticas de acesso à leitura e articulação das redes sociais. O programa foi lançado no segundo semestre de 2003, sob o argumento de que recolocaria a alfabetização de jovens e adultos como prioridade na agenda educacional do País. Com essa iniciativa, o governo federal assumiu para si a responsabilidade política e constitucional para a oferta de alfabetização de qualidade. Assim sendo, foi reforçada a concepção de que seja dever do Estado garantir a educação como direito de todos. 
Em que pese haver respaldo governamental acerca do programa e do Documento Nacional Preparatório da VI CONFINTEA - VI Conferência Nacional de Educação de Jovens e Adultos, realizada em dezembro de 2009, em Belém do Pará, e reconhecer a iniciativa como uma das ações estratégicas para a alfabetização de adultos, percebemos que as ações decorrentes do Brasil alfabetizado são realizadas em espaços não escolares, como associações e assentamentos. Não há, pois, envolvimento direto dos sistemas municipais, indicando assim que os processos de acompanhamento e de execução do programa podem ter comprometimentos de ordem didáticopedagógicos, como a falta de orientação didático-pedagógica, formação inicial e continuada e condições de trabalho, o que já pode ser identificado nos estudos de Lima (2012) ao analisar o programa em município da região do Mato Grande.

Contraditoriamente ao que ocorre nas escolas municipais e estaduais com as ofertas regulares, a pesquisa revelou deficiências na formação inicial dos profissionais que atuam junto ao programa Brasil Alfabetizado nos municípios pesquisados. Em João Câmara, dos 80 professores que atuam no programa, 70 só possuem o ensino médio. Em Touros, nenhum dos profissionais tem graduação, possuindo apenas o ensino médio. Apenas em Poço Branco e Taipu o número de docentes graduados supera os que têm o ensino médio, mas a quantidade de docentes não é tão ampla quanto em João Câmara e Touros.

Tais constatações indicam que a formação inicial ainda é um desafio para o trabalho docente e que para a EJA, em particular, alguns programas como o Brasil Alfabetizado contratam profissionais sem a devida formação, podendo prejudicar o processo de ensino-aprendizagem.

De acordo com os dados coletados pela pesquisa, o programa atende à comunidade indígena do amarelão, situada em João Câmara. O ProJovem Campo - Saberes da Terra é oriundo do programa Saberes da Terra, criado em 2005, estando vinculado à SECADI/MEC. Visa à escolarização de 5.000 jovens agricultores/as familiares, conforme definidos pela Lei 11.326/06, de diferentes estados e regiões do país. Inicialmente, o programa Saberes da Terra estava presente em apenas algumas unidades da Federação, tais como Bahia, Pernambuco, Paraíba, Maranhão e Piauí, região Nordeste; Mato Grosso do Sul, região Centro-Oeste; Santa Catarina e Paraná, região Sul; Minas Gerais, região Sudeste; Pará, Tocantins e Rondônia, região Norte.

Nos dois primeiros anos de sua existência, o programa Saberes da Terra atuou em comunidades ribeirinhas, quilombolas, indígenas, assentamentos e em comunidades de pequenos agricultores. Escolarizou adultos e se manifestou em experiências pedagógicas, tais como: "Encontros estaduais de educandos do Saberes da Terra", no Maranhão; "Pastas e utensílios da palha de bananeira", na Paraíba; "Projeto de produção agroecológica", no Pará; no Projeto "Mandala", no Mato Grosso do Sul; na "Noite da culinária camponesa" e nos "Projetos de vida dos educandos", no estado do Paraná; nos "Cadernos Pedagógicos", no Maranhão, Paraná e Tocantins.

O PNAD de 2006 indicou que de 6.276.104 jovens camponeses na faixa etária de 18 a 29 anos 1.641.940 não concluíram sequer o primeiro segmento do ensino fundamental, equivalente a $26,16 \%$, e 3.878 .757 (61,80\%) não concluíram a segunda etapa do ensino fundamental. Para enfrentar esses índices alarmantes de exclusão educacional, por meio de um esforço conjunto entre o Ministério da Educação por intermédio da Secretaria de Educação Continuada, Alfabetização e Diversidade (SECAD) e da Secretaria de Educação Profissional e Tecnológica (SETEC); o Ministério do Desenvolvimento Agrário por meio da Secretaria de Agricultura Familiar 
(SAF) e da Secretaria de Desenvolvimento Territorial (SDT); o Ministério do Trabalho e Emprego por meio da Secretaria de Políticas Públicas de Emprego (SPPE) e da Secretaria Nacional de Economia Solidária (SENAES); o Ministério do Meio Ambiente por meio da Secretaria de Biodiversidade e Floresta (SBF); o Ministério do Desenvolvimento Social e Combate à Fome (MDS) e a Secretaria Nacional de Juventude (SNJ) vinculada à Presidência da República, mediante a Medida Provisória no 411/07, o programa Saberes da Terra passou a integrar a Política Nacional de Inclusão de Jovens - PROJOVEM, passando a ser denominado de "ProJovem Campo - Saberes da Terra", com objetivo explícito de promover a reintegração do jovem ao processo educacional, sua qualificação profissional e seu desenvolvimento humano.

Em 2013, o campus João Câmara assumiu, no âmbito do IFRN, a coordenação geral da 2ạ edição da formação continuada do programa Saberes da Terra, em nível de Pós-graduação lato sensu e extensão universitária, atendendo a 320 professores e a 60 assistencionistas rurais. Apesar de não termos identificado na pesquisa os motivos reais, é curioso observar que, apesar de os municípios da região do Mato Grande apresentarem um elevado número de assentamentos e áreas rurais, como observam Azevedo, Tavares e Dantas (2011), apenas uma turma é atendida pelo programa junto aos municípios investigados.

Confrontando os dados da pesquisa, concluímos que o público-alvo do programa Saberes da Terra pode estar incluído naquele atendido pelo programa Brasil Alfabetizado, cujos espaços de funcionamento são assentamentos e áreas rurais, conforme observamos nos dados apresentados. Analisando por esse enfoque, podemos afirmar que, mesmo sendo iniciativas governamentais alocadas no conjunto de ações da SECADI/MEC voltadas à EJA, parece haver desarticulação entre os sistemas e os programas, além da falta de critérios e de acompanhamento nos processos de implementação.

Vemos ainda que todos os municípios apresentam, segundo as respostas, escolas que possuem projetos político-pedagógicos e que estes atendem às especificidades curriculares da EJA. Vale ressaltar que não foi possível definir linearmente os sujeitos da pesquisa, visto que as informações foram coletadas nas Secretarias Municipais de Educação, e que na maioria dos casos as respostas foram prestadas por diferentes profissionais, os quais variavam de acordo com o turno de trabalho. Ainda com relação ao aspecto mencionado, não foi possível também coletar e analisar os projetos político-pedagógicos, o que poderá ocorrer em estudos posteriores.

A situação já se altera quando se trata de um quadro específico de coordenadores pedagógicos para a EJA. Dos cinco municípios, quatro responderam que não há um quadro de profissionais específicos e, mesmo o que respondeu afirmativamente, explicita que são profissionais que atuam na Secretaria Municipal de Educação, e não especificamente nas escolas, podendo indicar que estas não dispõem de profissionais para atender e/ou trabalhar exclusivamente com a identidade da EJA. Tanto os dados da pesquisa quanto outros estudos, como os de Fiss (2010), revelam que o trabalho com a EJA deve ser norteado por processos formativos que observem as suas especificidades, sobretudo para se construir uma identidade frente ao trabalho docente.

Quanto ao planejamento, a pesquisa revelou que a metodologia é aquela tradicionalmente realizada pelos sistemas municipais de educação, isto é, encontros pedagógicos realizados anual e bimestralmente, reunindo geralmente todos os professores pertencentes ao quadro. Não foi possível identificar a metodologia de trabalho junto aos profissionais que atuam 
com a EJA, mas, ao analisarmos os indicadores de material didático-pedagógico e da formação continuada, podemos concluir que as práticas podem estar restritas a encontros generalistas e conteudistas, o que prejudica os processos de ensino-aprendizagem junto aos sujeitos jovens e adultos (SAMPAIO, 2009).

Ainda com relação ao planejamento, identificamos também que o material didáticopedagógico utilizado não corresponde, essencialmente, à educação de jovens e adultos, mas aquele que é distribuído para o ensino fundamental com enfoque nas ofertas dos estudantes regulares.

\section{CONSIDERAÇÕES FINAIS}

Vimos que a Educação de Jovens e Adultos (EJA) como direito socialmente garantido ainda é um desafio na realidade brasileira e na realidade local, notadamente nos municípios que compuseram a nossa investigação na região do Mato Grande, localizada no Rio Grande do Norte. Ingressamos no século XXI diante de uma série de desafios educacionais, sobretudo para as populações pobres e de regiões menos favorecidas socioeconomicamente, comportando realidades desiguais, que fazem com que as possibilidades e os desafios da educação permanente também estejam colocados para amplas parcelas da população, em particular para jovens e adultos que se encontram às margens do trabalho e dos processos educativos.

Assim, reafirmamos a necessidade de ampliar a percepção das dimensões de tempo e espaço no processo ensino-aprendizagem, bem como as propostas político-pedagógicas que atendem aos sujeitos jovens e adultos, devendo estabelecer uma relação mais estreita com o seu entorno sociocultural, visando ao desenvolvimento de práticas que vislumbrem uma escola associada à sua vida, à sua identidade e às suas especificidades.

Em que pese reconhecermos os avanços junto às iniciativas governamentais e não governamentais para os jovens e adultos, como a implementação do PROEJA, os dados oficiais continuam indicando que a EJA no Brasil ainda não ocupa uma posição privilegiada no conjunto das políticas de educação. Para ilustrar, vimos que a perspectiva de se atingir em $50 \%$ os níveis de alfabetização de adultos até 2015 não será mais possível, sendo prorrogada para 2025, caso as políticas, os programas e os projetos não se descontinuem, como histórica e politicamente vêm ocorrendo no Brasil.

A pesquisa revelou que dos cinco municípios investigados quatro responderam que não há um quadro de profissionais específicos e, mesmo o que respondeu afirmativamente, explicita que são profissionais que atuam na Secretaria Municipal de Educação, indicando que as escolas em particular não dispõem de profissionais para atender e/ou trabalhar exclusivamente com a EJA.

\section{REFERÊNCIAS BIBLIOGRÁFICAS}

1. AFONSO, Almerindo Janela. Os Lugares da Educação. In: SIMSON, O. R. de M. von; PARK, M. B.; FERNANDES, R. S. (Org.). Educação não formal: cenários da criação. Campinas: Unicamp, 2001. p. 29-38. 
2. ANTUNES, Ricardo. O continente do labor. São Paulo: Boitempo, 2011.

3. ARROYO, Miguel. A educação de jovens e adultos em tempo de exclusão: alfabetização e cidadania. Revista de Educação de Jovens e Adultos, São Paulo, n.11, p. 9-20, abr. 2001.

4. I Imagens quebradas: trajetórias e tempos de alunos e mestres. 5. ed. Petrópolis: Vozes, 2009.

5. _ _ Introdução: os coletivos diversos repolitizam a formação. In: DINIZ-PEREIRA, Júlio Emílio; LEÃO, Geraldo. (Org.). Quando a diversidade interroga a formação docente. Belo Horizonte: Autêntica, 2008.

6. AZEVEDO, Márcio Adriano de; SOUZA FILHO, Moysés. Projeto Político-Pedagógico e currículo no PROEJA: reflexões e fundamentos. In: CONGRESSO INTERNACIONAL DA AFIRSE COLÓQUIO NACIONAL, 5., 2009, João Pessoa, PB. Anais... João Pessoa, PB: [s. n.], 2009. p. 112.

7. _ _ _ TAVARES, Andrezza Maria Batista do Nascimento; DANTAS, Renier Cavalcanti. Nova ruralidade: concepções, embates e reflexões sobre particularidades na região do Mato Grande. In: TAVARES, Matheus Augusto Avelino; SEIXAS, Rebeka Caroca (Org.). Olhares sobre a região do Mato Grande. Natal: EDIFRN, 2011.

8. BEISIEGEL, Celso de Rui. Política e educação popular: a teoria e a prática de Paulo Freire no Brasil. 4. ed. Brasília: Liber Livro, 2008.

9. BRASIL. Senado Federal. Constituição da República Federativa do Brasil. Edição administrativa do texto constitucional promulgado em 5 de outubro de 1988, com as alterações adotadas pelas Emendas Constitucionais de Revisão n. 1 a 6/1994 e pelas Emendas Constitucionais n. 1/1992 a 39/2002. Brasília: Senado Federal, Subsecretaria de Edições Técnicas, 2003.

10. Construindo o Sistema Nacional Articulado de Educação: o Plano Nacional de Educação, Diretrizes e Estratégias de Ação: documento final. Brasília: MEC, 2010.

11. _. Ministério da Educação. Lei Federal no. 9.394, de 20.12.1996. Estabelece as diretrizes e bases da educação nacional. Diário Oficial da União, Brasília, DF, 23 dez. 1996. Seção 1, p. 27.8333-27.841.

12. Secretaria de Educação Profissional e Tecnológica. Programa Nacional de Integração da Educação Profissional com A Educação Básica na Modalidade de Educação de Jovens e Adultos - PROEJA: documento base. Brasília: MEC/SETEC, 2007.

13. DELORS, Jacques (Coord.). Educação: um tesouro a descobrir. 8. ed. Brasília: Cortez, 2003.

14. DIAS, Rosimeri de Oliveira. Deslocamentos na formação de professores: aprendizagem de adultos, experiência e políticas cognitivas. Rio de Janeiro: Lamparina, 2011.

15. DINIZ, Adriana Valéria Santos. As políticas de educação e de qualificação dos jovens e adultos e a transversalidade no currículo. Espaço do currículo, v.3, n.1, p.52-73, mar/set. 2009. Disponível em: <http:// www.aepppc.org.br/revista>. Acesso em: 15 jan. 2014.

16. FISS, Dóris Maria L. et al. (Org.). Identidades docentes I: educação de jovens e adultos, linguagens e transversalidades. Rio de Janeiro: Lamparina, 2010.

17. FREIRE, Paulo. Pedagogia da autonomia: saberes necessários à prática educativa. São Paulo: Paz e Terra, 2003. 
18. Pedagogia do oprimido. São Paulo: Paz e Terra, 1996.

19. GADOTTI, Moacir. Escola cidadã. Petrópolis: Cortez, 2013.

20. GOHN, Maria da Glória. Educação não formal e o educador social: atuação no desenvolvimento de projetos sociais. São Paulo: Cortez, 2010. (Coleção Questões da nossa época, 1).

21. HADDAD, Sergio; DI PIERRO, Maria Clara. Escolarização de jovens e adultos. Revista Brasileira de Educação, São Paulo, n. 14, maio/ago. 2000.

22. LIMA, Adriana Mônica Oliveira Ponciano de. Tecendo saberes na educação de jovens e adultos: olhares sobre o município de Pureza/RN. João Câmara, 2012, 104 f. Monografia (Especialização em Organização e Gestão para as modalidades de Educação de Jovens e Adultos e Educação do Campo) - Instituto Federal de Educação, Ciência e Tecnologia do Rio Grande do Norte, campus João Câmara, 2012.

23. MCLAREN, Peter. A Vida nas escolas: uma introdução à pedagogia crítica nos fundamentos da educação. Porto Alegre: Artes Médicas, 1996.

24. MOURA, Dante H. A implantação do PROEJA no CEFET-RN: avanços e retrocessos. Natal: [s. n.], 2008. Mimeografado.

25. O PROEJA e a Rede Federal de Educação Profissional e Tecnológica. Natal: [s. n.], 2006. Mimeografado.

26. RIO GRANDE DO NORTE. Plano de desenvolvimento sustentável do território do Mato Grande - RN. [S.I.]: Instituto Interamericano de Cooperação para a Agricultura (IICA), 2006.

27. ROMANS, Mercé. Formação continuada dos profissionais em educação social: profissão: educador social. Porto Alegre: Artmed, 2003.

28. SAMPAIO, Mariza Narcizo; ALMEIDA, Rosilene (Org.). Práticas de educação de jovens e adultos: complexidades, desafios e propostas. Belo Horizonte: Autêntica, 2009. (Coleção Estudos em EJA).

29. SCOCUGLIA, Afonso Celso. Pesquisa histórica da educação do tempo presente. Rev. Lusófona de Educação, n. 10, p. 27-40, 2004.

30. SOARES, Alexandre B. (Org.). Juventude e elos com o mundo do trabalho: retratos e desafios. São Paulo: Cortez; Campinas: CIESP; Rio de Janeiro: PUC-RIO, 2010.

31. UNESCO. Organização das Nações Unidas para a Educação, Ciência e Cultura. Educação para todos em 2015: alcançaremos a meta?: relatório de monitoramento de EPT - Brasil. Brasília: Unesco, 2008.

32. UNICEF. Fundo das Nações Unidas para a Infância. Acesso, permanência, aprendizagem e conclusão da educação básica na idade certa: direito de todas e de cada uma das crianças e dos adolescentes. Brasília: Unicef, 2012. 